Review

\title{
Mechanisms of realization of THz-waves of nitrogen oxide occurrence physiological effects
}

\author{
Vyacheslav F. Kirichuk, Alexander A. Tsymbal, Evgeny V. Andronov
}

Saratov State Medical University n.a. V.I. Razumovsky, Saratov, Russia

Received 20 May 2013, Accepted 23 August 2013

(C) 2013, Kirichuk V.F., Tsymbal A.A., Andronov E.V.

(C) 2013, Russian Open Medical Journal

Abstract: In this review, there is generalized material of many experimental researches in interaction of THz-waves molecular emission and absorption spectrum (MEAS) of nitrogen oxide occurrence with bioobjects. Thrombocytes and experimental animals were used as bioobjects. The experiments let indicate changes caused by THz-waves: at the cellular, tissular, system, organismic levels. There are all data of changes in physiological mechanisms of reglations at all levels: autocrine, paracrine, endocrine and nervous. There is a complex overview of experimental material firstly performed in the article. There had been shown that the effect of THz-waves of the given occurrence is realized by the changed activity of nitroxidergic system. It had been proved that THz-waves of nitrogen oxide occurrence can stimulate nitrogen oxide producing in organs and tissues in condition of its low concentration. Possible mechanisms of antiaggregative effect of the given waves had been described. There had been shown the possibility of regulating of vascular tone and system hemodynamics with the help of the studying these frequencies. The represented data of lipid peroxidation and enzymatic and nonenzymatic components of organism system under the influence of THz-waves of nitrogen oxide occurrence in stress conditions. Besides, there were shown changes of stress-regulating system activity and in concentration of important mediators - catecholamines and glucocorticosteroids. These data let characterize mechanism of realization of THz-waves basic effects. The research had shown the possibility of THz-waves of nitrogen oxide occurrence usage as a method of natural physiological noninvasive regulation of significant organism functions.

Keywords: $\mathrm{THz}$ waves, nitrogen oxide

Cite as Kirichuk VF, Tsymbal AA, Andronov EV. Mechanisms of realization of THz-waves of nitrogen oxide occurrence physiological effects. Russian Open Medical Journal 2013; 2: 0404.

Correspondence to Prof. Vyacheslav F. Kirichuk. Address: Department of normal physiology n.a. I.A. Chuevsky, Saratov State Medical University n.a. V.I. Razumovsky, 112, Bolshaya Kazachiya str., Saratov, 410012, Russia. E-mail: normalf@yandex.ru

THz-therapy is relatively new but perspective method of physiotherapeutic exposure [1]. THz band is on the board of electronics and photonics from $100 \mathrm{GHz}$ to $10 \mathrm{THz}(1 \mathrm{THz}=$ $103 \mathrm{GHz}$ ) or in wave length from $3 \mu \mathrm{m}$ to $30 \mu \mathrm{m}$. At the top it is determined by time-and-frequency limit (more than100 GHz), and below - by the maximal wavelength of a quantum transition of laser structures [1].

The molecular emission and absorption spectrums (MEAS) of many biologically active substances (nitrogen oxide, carbon oxide, molecular oxygen and its active forms, etc.) are in $\mathrm{THz}$ band [2, 3]. Among these metabolites the most significant in regulation of physiological processes is nitrogen oxide (NO).

The NO is a colorless gas, water soluble, one of the most elementary substances with odd number of electrons. Radical properties of nitrogen oxide are determined by the ability to react with different connections and free radicals. One of nitrogen oxide features is an intra- and intercellular secondary messenger. The features of an intra- and intercellular secondary messenger are peculiar to nitrogen oxide, it is also a paracrine connection, as it can influence on the functions of different neighboring cells [4].

Endogenic nitrogen oxide synthesizes in organs, tissues and cells by fermentation method with NO-synthase (NOS) (family of cytochromes $\mathrm{P}_{450}$ ferments) using $\mathrm{L}$-arginine amino acid as a substrate [5].

Nitrogen oxide is a significant mediator in human and animal organisms; it regulates different organs and systems action. It takes part as in nervous as in humoral regulations, provides local and system regulatory reactions. The major role of nitrogen oxide is regulation of a cardiovascular system and determination of microcirculation function [4]. Taking into account a significant role of microvessels in cardiovascular system function, the developing of the supporting methods of physiological concentration and regulating of endogenic nitrogen oxide synthesis are of a certain scientific and practical interest. Today there different drugs, with nitrogen oxide donors effect, are used in medicine. Though, pharmacotherapy is always accompanied by a variety of side effects of different degrees [6]. So there are new nondrug correction methods searching [7]. One of these methods is a usage of electromagnetic irradiation of millimeter and submillimeter bands.

The experiments in the interaction of electromagnetic irradiation of $\mathrm{THz}$ band of nitrogen oxide occurrence with bioobjects let reveal some positive effects of these waves which could be used in clinical practice for normalizing of a system hemodynamics and microcirculation. The great scientific interest generates mechanism of realization of these effects. 
Today there had been presented several paradigms of the mechanisms of influencing on bioobjects (at the cellular, molecular, organismic levels) of electromagnetic irradiations (EMI) of millimeter and submillimeter bands. The most complete method is described in the studies [8-11].

One of the possible mechanisms of $\mathrm{THz}$ irradiation of the MEAS of $150.176-150.664 \mathrm{GHz}$ nitrogen oxide occurrence may be the change of receptor cellular apparatus. This mechanism had been suggested to explain antiaggregant influence of classical extremely-high frequencies (EHF) radiations [12]. The point is in induction of millimeter and submillimeter bands of conformational changes in glycoprotein receptors and associated with it thrombocytic membrane, and change in glycoprotein complex hydratation. This may cause the defect of connection between receptor and high-molecular ligands, fibrinogen first of all. These changes could have inhibiting effect on thrombocytes aggregation. This fact was confirmed by our research of thrombocytes receptor apparatus.

The study of thrombocytes aggregation induced by lectins had shown that in THz irradiation of the MEAS of 150.176$150.664 \mathrm{GHz}$ nitrogen oxide occurrence of white male rats under the acute immobilization stress condition, there was a reduction of phytohemagglutinin-induced thrombocytes aggregation, which indicates change in glycoprotein thrombocytes receptors. Change in phytohemagglutinin-induced thrombocytes aggregation may be connected as with the reduction of the receptors expression as with their activity defect, probably because of their fluctuation in phospholipid membrane bilayer or because of conformational changes and hydratation [13].

Another possible mechanism of the influence of $\mathrm{THz}$ irradiation of the MEAS of NO is endogenic nitrogen oxide activation [7]. According to one of the theories [10], during the irradiation the energy of the $\mathrm{THz}$ irradiation is expended for the transformation from one energetic condition into another one. The usage of concrete density levels in medical practice exogenic exposure of electromagnetic irradiation leads to change in rotational component of molecular energy. When the frequency of the irradiation coincides with a rotational frequency of polar molecules, there can be running of the irradiation energy to a molecule, which influences its reaction ability. There is a possible interaction of $\mathrm{THz}$ waves and NOS. The result of it can be the acceleration of intramolecular electron transfer [5], which leads to an increase of catalysis speed. Besides, there can be an interaction of $\mathrm{THz}$ irradiation and heme of NOS and/or guanylatecyclase (is the main aim of endogenic nitrogen oxide leading to its transformation into a high-spin state, accompanied by an increase of sensitivity of NO-synthase to L-arginine and an increase of ferment activity).

So during the $\mathrm{THz}$ irradiation of the MEAS of NO there is a possible increase of reaction ability and/or endogenic nitrogen oxide concentration.

This theory is confirmed by several facts. It had been established that irradiation of the animals under the oxidative stress by the 15-minute THz irradiation of the MEAS of $240 \mathrm{GHz}$ NO leads to a complete normalization of thrombocytes aggregation parameters and maximal speed of the most thrombocytic aggregates producing, and partial normalization of maximal speed of thrombocytes aggregation. But NOS-inhibitor LNAME in $4 \mathrm{mg} / \mathrm{kg}$ blocks the normalizing effect of $\mathrm{THz}$ irradiation of the MEAS of NO on the defected thrombocytes aggregation ability in animals under the oxidative stress [14].
On the other hand it was shown that the injection of NO Isoket donor at the in vitro conditions in the patients with unstable angina into the whole blood with hyperviscosity leads to more significant decrease of a blood viscosity, if NO Isoket donor had been irradiated by 15 -minute $\mathrm{THz}$ irradiation of the MEAS of $240 \mathrm{GHz}$ NO. These facts indicate that the significant meaning has the regulation of nitrogen oxide production and reaction ability [15] in realization of biological effect of electromagnetic waves of $\mathrm{THz}$ band.

To estimate the concentration of endogenic nitrogen oxide synthesis together with the direct measuring of NO-synthase activity (according to citrulline producing) there is used a concentration of stable metabolites - nitrites and nitrates. The concentration of nitrites is an objective criterion of a nitroxidergic system activity [16].

We had established that irradiation of white male rats under the immobilization stress by the electromagnetic waves of $\mathrm{THz}$ band of the MEAS of $150 \mathrm{GHz}$ NO leads to an increase of concentration of nitrites in blood plasma comparing with the animals under the acute immobilization stress which had not been irradiated.

Nominally we can distinct three levels of realization of NO activity increasing effect after $\mathrm{THz}$ irradiation: direct influence on cells - autocrine influence; influence on tissues - paracrine regulation of neighboring cells action and central effects - NOdependent changes in nervous and humoral regulation.

Direct influence on thrombocytes activity is caused by guanylatecyclase because of nytrozil-heme complex [17]. The realization of this exposure of electromagnetic waves of the MEAS of NO is studied experimentally at in vitro by V.F. Kirichuk et al. $[18,19]$. The experiments were organized on thrombocytes in the patients with unstable angina, and confirmed after irradiating of the animals at in vivo condition [7]. The guanylatecyclase activation leads to a concentration of cycle guanosine monophosphate in thrombocytes which inhibits $\mathrm{Ca}^{2+}$ ions into cytoplasma and blocks the activation of inositoltriphosphate, which is a basic mechanism in of induction of blood platelets aggregation [17].

The example of paracrine action may be ejection of endothelial cells as nitrogen oxide as a number of biologically active substances which are regulated by nitrogen oxide. The production of nitrogen oxide is a base of endothelium-dependent vasodilatation [20]. The performed experiments in linear blood flow rate in great vessels at the acute immobilization stress conditions indicated that the 5-, 15- and 30-minute $\mathrm{THz}$ irradiation of the MEAS of $150.176-150.664 \mathrm{GHz}$ nitrogen oxide occurrence leads to a decrease of an increased linear blood flow rates (systolic and diastolic) and pressure gradient in abdominal aorta and femoral arteria which indicates the vasodilation of these vessels [21].

The significant components of tissue homeostasis are lipid peroxidation processes in tissue and antioxidant systems. An increase of lipid peroxidation products concentration on in relation to stationary level is considered as a universal mechanism of cell damage at different pathological conditions. There had been shown, that in influence of $\mathrm{THz}$ irradiation of the MEAS of 150.176-150.664 GHz nitrogen oxide occurrence on the animals under the immobilization stress, there is a normalization of lipid peroxidation processes and antioxidant activity. This is appeared in a reduction of toxical lipid peroxidation intermediate products lipid hydroperoxides, malondialdehyde. In the 30-minute $\mathrm{THz}$ 
irradiation of the MEAS of $150.176-150.664 \mathrm{GHz}$ nitrogen oxide occurrence there is an effective normalization of antioxidant systems activity - its enzymatic and nonenzymatic components, this is reflected in the fact of normalization of superoxide dismutase and catalase activity in erythrocytes and general sulfhydryl groups and vitamin $\mathrm{E}$ in blood serum up to intact animals level.

Nitrogen oxide is a strong regulator of lipid peroxidation. At physiological conditions it displays antioxidant properties, blocks peroxidation processes, but in pathology it can be a strong prooxidant (transforming into peroxynitrite). An increase of enzymatic component of antioxidant system (superoxide dismutase) blocks superoxide anion and peroxynitrite producing - overconcentration of nitrogen oxide with the help of $\mathrm{THz}$ waves and an increase of superoxide dismutase have protective, but not pathological damaging character, which shows the safety of physiotherapeutic method.

Individual attention is for NO-dependent changes of neurohumoral regulation of an organism functions. At present time there is formed an idea of a nitrogen oxide generation system as of a separate stress-limiting system. It is activated after the influence of different stress factors and in the process of adaptation to repeated exposures $[22,23]$. NO-ergic system is tightly connected with other stress-limiting systems. So nitrogen oxide potentiates GABA (gamma-aminobutyric acid)-ergic system by blockade of GABA-transaminase [24], this leads to an increase to GABA concentration and stimulates release of opioid peptide in brain, and as a result potentiates opioid- ergic stress-limiting system [25].

An increase of NO-ergic stress-limiting system probably explains a stronger effect of $\mathrm{THz}$ irradiation of the MEAS of nitrogen oxide occurrence, because at this irradiation mode a hyperproduction of stress hormones is blocked which develop typical microcirculation defects. The received results are correlated with experimental research of other authors. So E.N. Chuyan et al. [26] had shown that stress-limiting effect of EMI of EHF with wave length of 5.6 and $7.1 \mathrm{~mm}$ depends on a sequence of electromagnetic irradiation exposure.

An activation of NO-ergic neurons in the central nervous system prevents a hypersecretion of the basic hypotalamohypophysial stress hormones, as corticotropin, releasing-factor of corticotrophin, etc. [27]. It is known that corticotrophin regulates glucocorticosteroid producton by adrenal cortex [20]. Experimental research had indicated that $\mathrm{THz}$-irradiation of the MEAS of $150.176-150.664 \mathrm{GHz}$ nitrogen oxide occurrence on white male rats can prevent an increase of corticosteroid level in irradiation before stressor activation; it means that these results indicate the limitation of hypotalamo-hypophysial-adrenal axis of stress reaction [28].

NO-ergic neurons innervate adrenal medulla directlycontact with pheochrome cells, during their activation they block the producing of catecholamines by adrenal cortex [29]. Besides, nitrogen oxide can block catecholamines in nerve-endings [23, 29]. The results of the research indicated that in irradiation of animals under the acute immobilization stress by the electromagnetic waves of THz-irradiation of the MEA of $150.176-150.664 \mathrm{GHz}$ NO occurrence, there is a statistically valid reduction of catecholamines concentration in blood which shows a limitation of sympatho-adrenal axis of stress reaction.
However, the results of the experiments, catecholamines concentration and glucocorticoids in blood of animals after $\mathrm{THz}$ irradiation of the MEAS of $150.176-150.664 \mathrm{GHz}$ NO occurrence before immobilization, is not at the level of the control group, but increases nominally. This fact shows that $\mathrm{THz}$ irradiation does not block the stress reaction which would defected the adaptation process, but modulate its progressing blocking an overactivation of stress-realizing systems. Thus $\mathrm{THz}$ irradiation preceding stress, changestress reaction developing, increases stress resistance in animals.

So at the experimental condition in animals we had received new results of mechanisms of $\mathrm{THz}$ irradiation of the MEAS of 150.176-150.664 GHz NO occurrence on changes in a stressed organism.There search reveals several physiological effects of this irradiation at the cellular, molecular, tissular, system, and organismic levels. All levels of physiological regulation are involved into realization of $\mathrm{THz}$ irradiation effects - from neuro-endocrinal changes to auto-regulation of cells.

The received data let recommend the usage of electromagnetic waves of THz irradiation of the MEAS of 150.176$150.664 \mathrm{GHz}$ NO occurrence in clinical practice for normalization of system hemodynamics and microcirculation in different diseases, including cardiovascular diseases, and as a method of strong antistress effect. The results of the research are experimental validation for development and introduction it into practical medicine, together with "Terahertz therapy" - new departure of phydiotherapy - "THF-prevention".

Conflict of interest: none declared.

\section{Reference}

1. Betsky OV, Krenitsky AP, Maiborodin AV. Biophysical effects of THzband and perspectives of progress in a new direction in biomedical technologies. Biomedical Radioelectronics 2003; (12): 3-6. [Article in Russian]

2. Betsky OV, Krenitsky AP, Maiborodin AV, et al. Molecular HITRANspectra of metabolites gas in THz and IR bands, and their usage in biomedical technologies. Biomedical Radioelectronics 2007; (7): 5-9. [Article in Russian].

3. Rothman LS, Barbe A, Benner CD, Brown LR, Camy-Peyret C, Carleer $M R$, et al. The HITRAN molecular spectroscopic database: edition of 2000 including updates through 2001. Journal of Quantitative Spectroscopy \& Radiative Transfer 2003; 82: 5-44. (doi: 10.1016/S0022-4073(03)00146-8)

4. Ignarro LJ, Cirino G, Casini A, Napoli C. Nitric oxide as a signaling molecule in the vascular system: an overview. J Cardiovasc Pharmacol 1999; 34(6): 879-886. (PMID: 10598133)

5. Gorren ACF, Mayer B. The versatile and complex enzymology of nitric oxide synthase. Biochemistry (Moscow) 1998; 63(7): 734-743. (PMID: 9721327)

6. Münzel T, Daiber A, Mülsch A. Explaining the phenomenon of nitrate tolerance. Circulation Research 2005; 97: 618-628. (PMID: 16195486) (doi: 10.1161/01.RES.0000184694.03262.6d)

7. Kirichuk VF, Ivanov AN, Antipova ON, Krenitskiĭ AP, Maĭborodin AV, Tupikin VD, Betskiĭ OV. Effect of SWF-radiation on thrombocytes and erythrocyte functions of albino rats upon stress condition. Tsitologiia 2005; 47(1): 64-70. (PMID: 16602245) [Article in Russian]

8. Devyatkov ND, Golant ND, Betsky OV. Millimeter-waves and their role in vital processes. Radio and Communication Publ., Moscow, Russia, 1991. [Text in Russian]

9. Betsky OV. Mechanism of low-intensity millimeter-waves exposure on biological objects (biophysical method). In: Millimeter Waves in 
Biology and Medicine. Moscow, Russia, 1997: 135-137. [Text in Russian]

10. Betsky OV, Deviatkov ND, Kislov VV. Low-intensity MM-waves in biology and medicine. Biomedical Radioelectronics 1998; (10): 13-29. [Article in Russian]

11. Betsky OV, Lebedeva NN. Modern conceptions of mechanisms of lowintensity millimeter-waves on biological objects. Millimeter Waves in Biology and Medicine 2001; (3): 5-18. [Article in Russian]

12. Kirichuk VF, Krenitcky AP, Maiborodin AV, Tupikin VD. Microcirculation and electromagnetic waves of Thz-band. Saratov State Medical University Publ., Saratov, Russia, 2006. [Book in Russian]

13. Ivanov AN, Karavaikin PA. Revelation of various carbohydrate remains in the structure of glycoprotein receptors on a surface of cytoplasmic thrombocyte membrane using lectins, and studying of immobilization stress influence on expression degree of glycoprotein receptors. In: The $68^{\text {th }}$ scientific conference of young scientists of Saratov State Medical University. Saratov, Russia, 2007: 135-136. [Text in Russian]

14. Andronov EV. Experimental studying of the effect of electromagnetic waves of terahertz band of nitrogen oxide occurrence on intravascular microcirculation component. Abstract of D.Sc. degree study. Saratov, Russia, 2008. [Text in Russian]

15. Kirichuk VF, Andronov EV, Mamontova NV, Tupicin VD, Mayborodin AV. Use of terahertz electromagnetic radiation for correction of blood rheology parameters in patients with unstable angina under conditions of treatment with isoket, an NO donor. Bull Exp Biol Med 2008; 146(3): 293-296. (PMID: 19240843)

16. Karpiuk VB, Cherniak US, Shubin MG. Laboratory monitoring of nitroxidergic vasorelaxation in subarachnoid hemorrhage. Clinical and Laboratory Diagnostics 2000; (5): 16-19. [Article in Russian]

17. Severina IS. Role of soluble guanylate cyclase in the molecular mechanism underlying the physiological effects of nitric oxide. Biochemistry (Mosc) 1998; 63(7): 794-801. (PMID: 9721331)

18. Kirichuk VF, Volin MV, Krenitcky AP, et al. Thrombocytes in hemostasis system reactions on EHF exposure. Saratov State Medical University Publ., Saratov, Russia, 2002. [Book in Russian]

19. Kirichuk VF, Maiborodin AV, Volin MV, et al. The laws of functional thrombocytes activity shifts in the electromagnetic waves of EHF variationsof the MEAS of nitrogen oxide occurrence. In: The $12^{\text {th }}$ Russian international academic conference "Millimeter waves in biology and medicine", Moscow, Rusia, 2001: 96-97. [Text in Russian]

20. Kirichuk VF. Regulation of organism functions. Humoral regulation. Saratov State Medical University Publ., Saratov, Russia, 2008. [Book in Russian]

21. Kirichuk VF, Corableva TS, et al. Method of normalization of defectedlinear blood flow rate in great vessels in the acute stressreaction at the experimental conditions. Patent [rus] №2327493, 27.06.2008.

22. Malyshev IY, Manukhina EB. Stress, adaptation, and nitric oxide. Biochemistry (Mosc) 1998; 63(7): 840-53. (PMID: 9721337)

23. Manuhina EB, Malyshev IYu. Nitrogen oxide stress-limiting system. Russian Physiol Journal n.a. I.M. Sechenov 2000; 86(10): 1283-1292. [Article in Russian]

24. Paul V, Jayakumar AR. A role of nitric oxide as an inhibitor of garnmaamonobutyric acid transaminase in rat brain. Brain Res Bull 2000; 51 : 43-46. (PMID: 10654579) (doi: 10.1016/S0361-9230(99)00206-3)

25. Aimstead WM. Nitric oxide contributes to opioid release from glia during hypoxia. Brain Res 1998; 813: 398-401. (PMID: 9838202) (doi: 10.1016/S0006-8993(98)01022-1)

26. Chuian EH, Temuriantc NA, Moskvichuk OB, et al. Physiological mechanisms of biological effects of the low-intensity EMI of EHF. Simferopol, Ukraine, 2003. [Text in Russian]

27. Kostoglou-Athanassiou I, Costa A, Navarra P, Nappi G, Forsling ML, Grossman AB. Endotoxin stimulates an endogenous pathway regulating corticotropin-releasing hormone and vasopressin release involving the generation of nitric oxide and carbon monoxide. J Neuroimmunol 1998; 86: 104-109. (PMID: 9655478)
28. Tsymbal AA. Change in corticosterone concentration - acute and chronic stress marker and terahertz therapy. In: Interregional conference on V.I. Razumovsky's $150^{\text {th }}$ birthday anniversary. Saratov, Russia, 2007: 175-176. [Text in Russian]

29. Addicks K, Bloch W, Feelisch M. Nitric oxide modulates sympathetic neurotransmission at the prejunctional level. Microsc Res Technique 1994; 29(2): 161-168. (PMID: 7529070)

\section{Authors:}

Vyacheslav F. Kirichuk - MD, D.Sc. Professor, Honored Scientist of Russia, Head of Department of Normal Physiology n.a. I.A. Chuevsky, Saratov State Medical University n.a. V.I. Razumovsky, Saratov, Russia;

Alexander A. Tsymbal - MD, PhD, Associate Professor, Department of Normal Physiology n.a. I.A. Chuevsky, Saratov State Medical University n.a. V.I. Razumovsky, Saratov, Russia;

Evgeny V. Andronov - MD, D.Sc., Professor, Department of Norma Physiology n.a. I.A. Chuevsky, Saratov State Medical University n.a. V.I. Razumovsky, Saratov, Russia. 